\title{
U.S. FDA and FTC: Opioid Addiction and Health Fraud
}

LCDR Jeffery L. Sumter, DrPH; CDR Adrienne Goodrich-Doctor, PhD.

$54^{\text {th }}$ USPHS Scientific \& Training Symposium, Minneapolis Convention Center, Minneapolis, MN

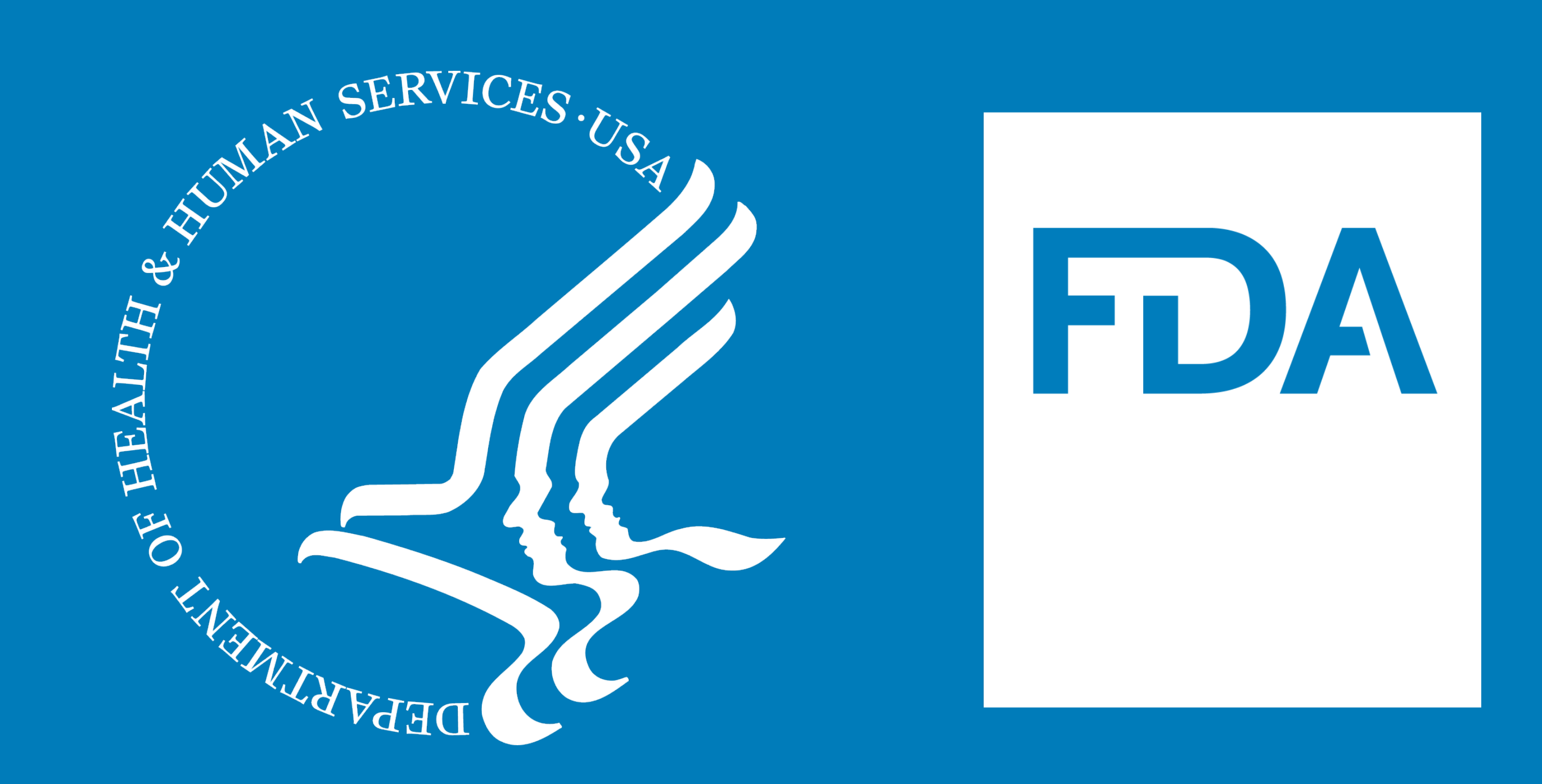

\section{Introduction}

Opioid addiction is a serious health epidemic that affects millions of Americans. Opioids are a class of drugs that include: the illegal drug heroin rescription, such as: oxycodone, hydrocodone, codeine, morphine an thers. In part, increased prescription of opioid medications have led to widespread misuse of both prescription and non-prescription opioids, and
resulted in an opioid addiction epidemic. Consumers with opioid addiction may seek medication-assisted treatments (MAT) or dietary supplements (DS) to treat opioid withdrawal. Treatments such as buprenorphine and methadone have been demonstrated to be safe and effective in combin
with counseling and psychosocial support. There is strong scientific
evidence that this combination of therapeutic interventions is life-saving nd can enable people to recover to healthy lives. However, there are imited drugs approved by the U.S. Food and Drug Administration (FDA) for opioid addition treatment.

ome marketers and distributors are illegally marketing products with addiction and withdrawal. Such products have not been demonstrated to safe or effective and may keep some consumers from seeking appropriate, DA-approved therapies. Health fraud scams can pose serious health risk opioid addiction and withdrawal is a violation of the Federal Food, Drug, and Cosmetic Act (FD\&C) Act, and making unsubstantiated therapeutic chims are also a violation of the Federal Trade Commission Act, which prohibits deceptive advertising. It is unlawful to make any deceptive representation with respect to the cost, price, efficacy, perfor
benefit, risk, or safety of any MAT or dietary supplement.

FDA aims to reduce the number of Americans addicted to opioids, cut the rate of new addictions and promote innovative access to MAT for more than 2-million Americans with an opioid use disorder (OUD).
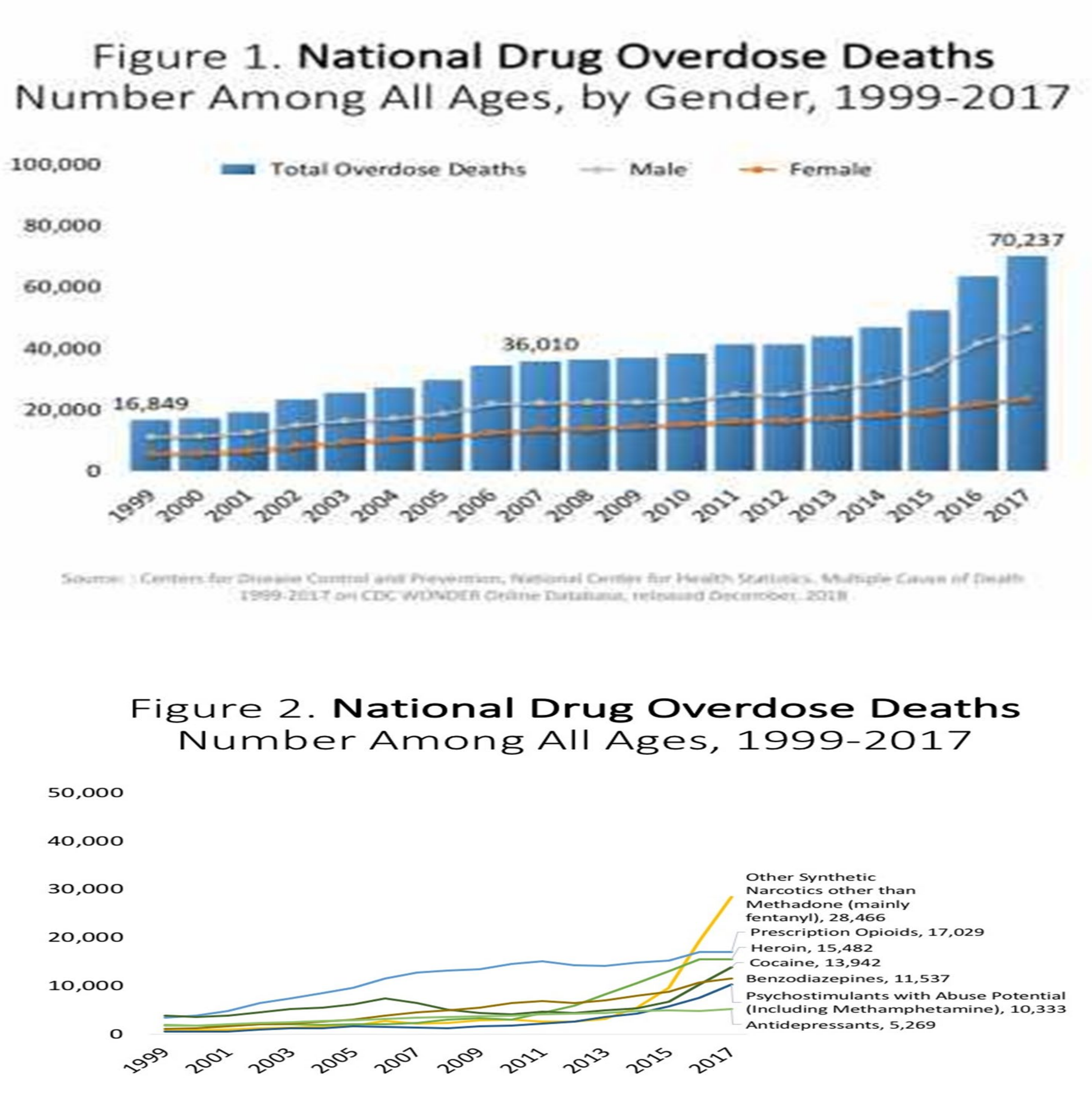

\section{Intervention}

In 2018, FDA and the Federal Trade Commission (FTC) reviewed marketing claims on opiate withdrawal treatments. The results of the review revealed that some marketers and distributers illegally marketed products with unproven treatment claims. Both the FD\&C and FTC Acts or cure a disease or other heath condition, must be supported by competen or cre a disease or other heath condition, must be supported by compete
and reliable scientific evidence. Therefore, it is unlawful to make health claims, whether directly or indirectly, through labels, labeling, advertising. the use of a product name, website name, or any other means, without
adequate scientific support, or to exaggerate the benefits of products or
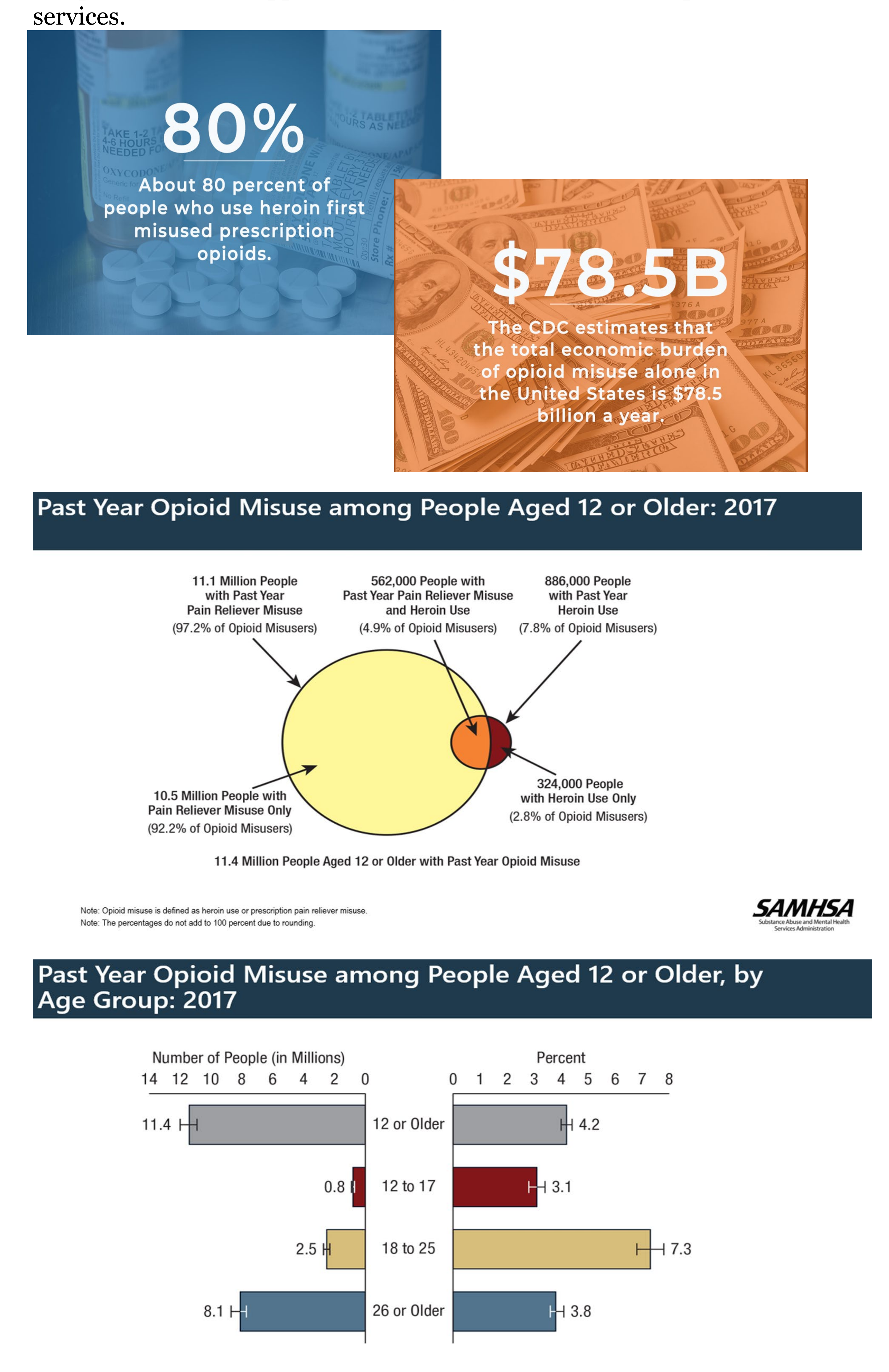

\section{Actions}

In response to the review of claims on opiate withdrawal treatments, the In response to the review of claims on opiate withdrawal treatments, the
FDA and FTC found some marketers and distributers illegally marketed
products with unproven treatment claims. FDA and FTC took action by products with unproven treatment claims. FDA anale claims, reminding issuing letters to 16 firms that used such questionable claims, reminding
them that they needed solid scientific proof to support all health claims conveyed to consumers, especially representations about serious condition
like opioid dependence. The manufacturers were strongly urged to review all health-related claims by the firms' and any of their affiliates on all mediums.
The FDA and FTC issued joint warning letters to 11 firms for their products
The FTC sent four additional warning letters to other marketers of opioid The FTC sent four additional warning letters to other marketers of opioid online platforms to make unproven claims about their product's ability to cure, treat, or prevent OUD. Examples of such claims are listed below:

“\#1 Selling Opiate Withdrawal Brand"

"Imagine a life without the irritability, cravings, restlessness, excitability, withdrawal symptoms."
"Safe and effective natural supplements that work to ease many physical "Brmptoms of opiate withdraw

"Relieve Your Symptoms....addiction, withdrawal, cravings."

In addition, both the FDA and FTC reexamined their approach to pomeopathic products (HP). Each agency adopted new enforcement products making drug related claims, including claims that such products can treat specific conditions. FDA's new enforcement approach also covers products labeled as homeopathic that contain potentially harmful
ingredients or do not meet current good manufacturing practices.

FDA regulates HP as drugs, whereas it regulates dietary supplements (DS) as food. However, many DS contain ingredients with strong biological
effects and some may contain hidden drugs that are falsely marketed as DS, thus putting consumers at risk. Recently, FDA has seen an increased
umber of companies illegally marketing DS and HP compounds for the umber of companies illegally marketing DS and. HP conpounds for the

(1)

$$
\overbrace{\text { FRAUD }}^{\text {REPORT }}
$$
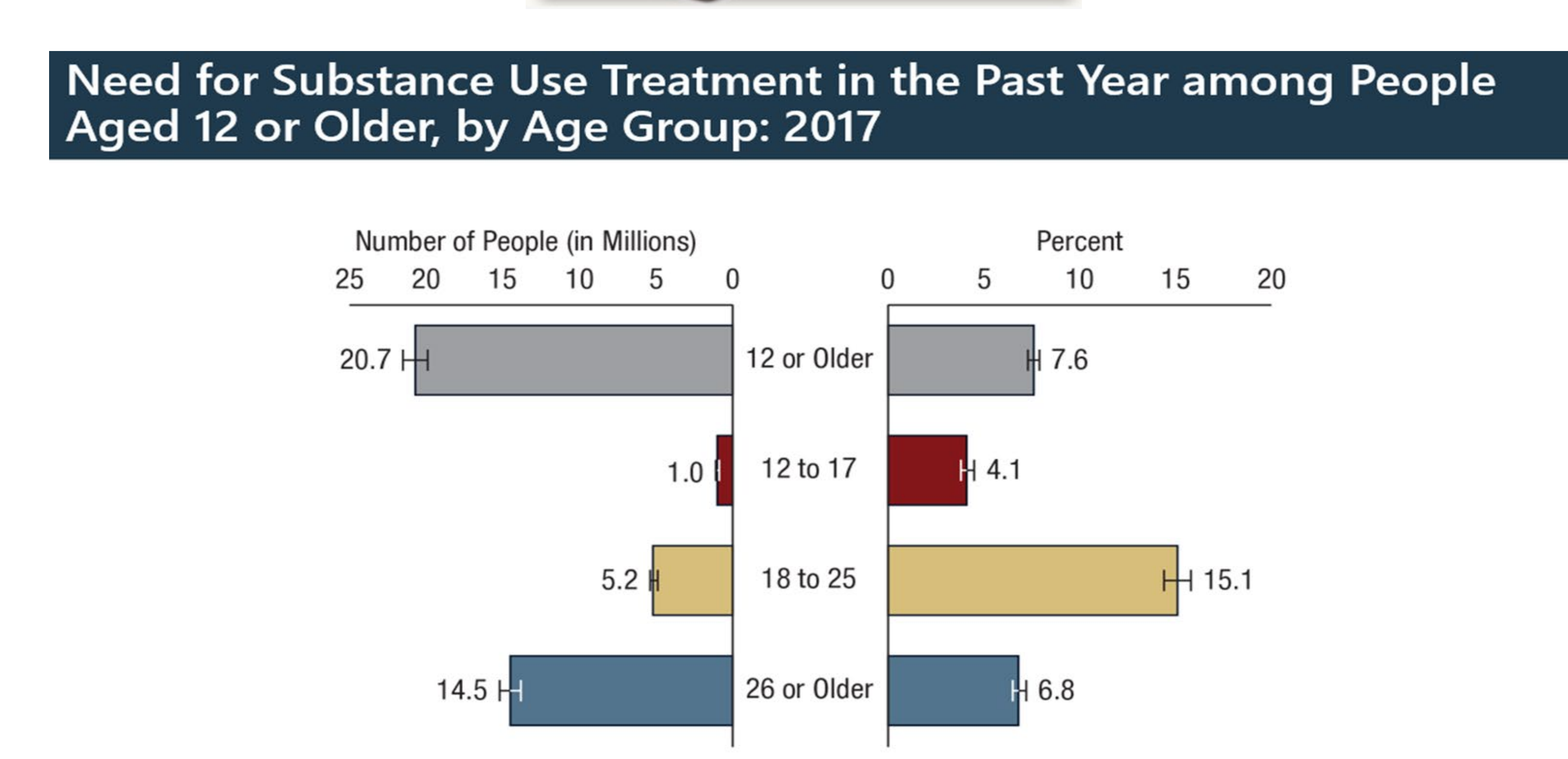

\section{Getting the Right Help}

Do you know someone seeking treatment for opioid dependence or
withdrawal? If so it's important to know this: products that promise withdrawal? If so, it's important to know this: products that promise
miracle cures or fast results can cost precious time and money, lead to
relapse, and even be dangerous.

Dietary supplements - such as herbal blends, vitamins, and minerals have not been scientifically proven to ease withdrawal or to treat opioid dependence.

Products like Kratom, which some claim can help, are actually not roven treatments, and can be addictive and dangerous to your healt Opioid dependence and withdrawal are serious health issues. You caa
address them with time, hard work, and help. But there are no quick

Before taking any dietary supplement - for any medical reason - ask a health provider these questions:

- Is there scientific proof it actually works?

How will it interact with o

What are the side effects?
If it's safe to take, what's the right amount?

\section{Conclusion}

To follow-up on the 2018 Warning Letters, FDA will coordinate a series
inspections which include firms producing products labeled as dietary supplements but marketed as unapproved opioid addiction and withdrawal treatments. During inspections, FDA will seek to remove misbranded and
potentially harmful products from the market. While FDA has a role in the enforcement of federal laws, it also encourages innovation and the

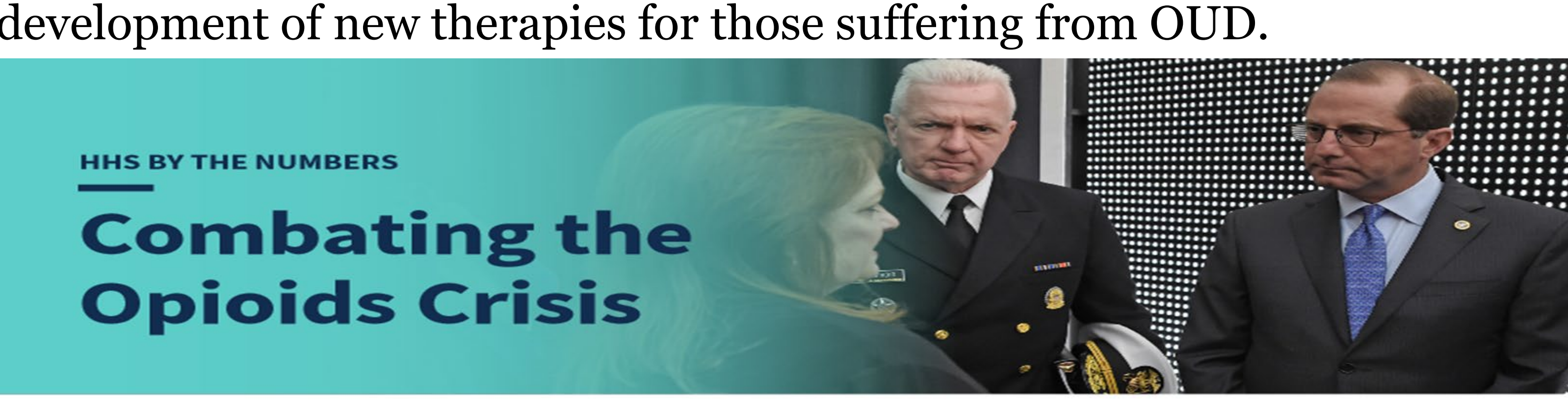

367\% $\cap$ S2 BILLION+

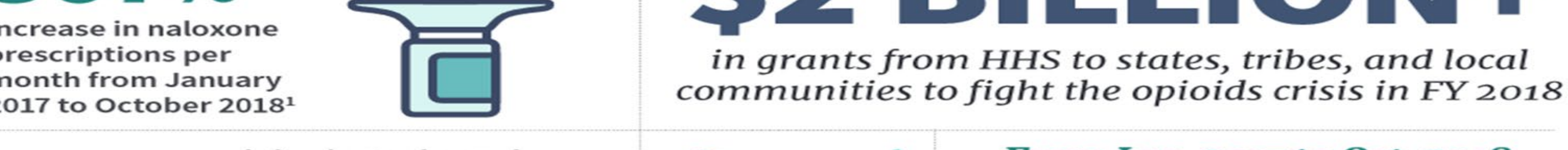

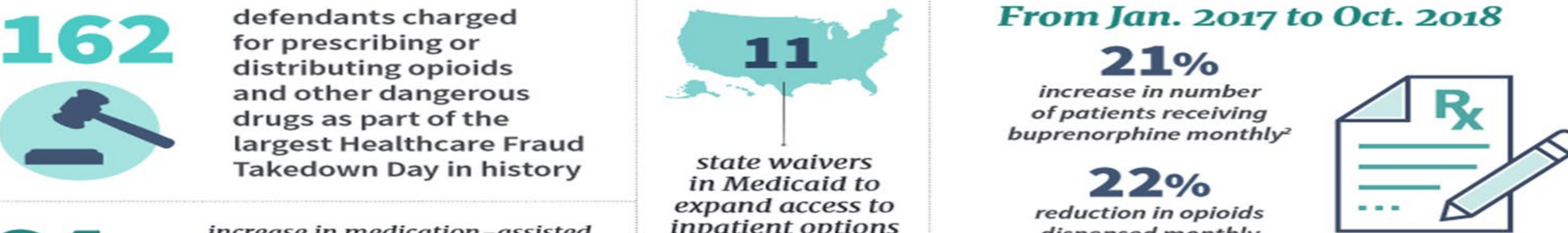

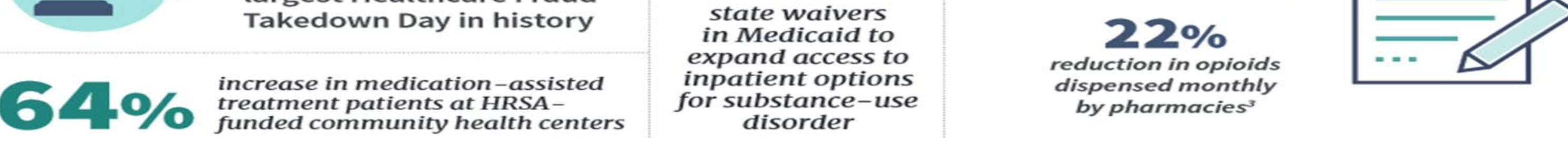

Acknowledgements and Contacts Health care professionals and consumers are encouraged to report any
dverse events related to these products to the FDA's MedWatch Adverse adverse events related to these peporting program. To file a report, use the MedWatch Online Voluntary Reporting Form. The completed form can be submitted online or 